\title{
Blood parameters changes in cord blood of newborns of hypertensive mothers
}

\author{
Ahmet Bolat • Orhan Gursel • Emin Kurekci • \\ Avni Atay • Okan Ozcan
}

Received: 22 March 2013 / Accepted: 11 June 2013 /Published online: 29 June 2013

(C) The Author(s) 2013. This article is published with open access at Springerlink.com

\begin{abstract}
The aim of this study was to investigate the changes in the peripheral blood of newborns of hypertensive mothers. The umbilical cord blood from newborns of 31 hypertensive mothers and 32 healthy mothers were examined. In all subjects, complete blood count, peripheral blood smear, reticulocyte count, vitamin $B_{12}$, folate, ferritin levels and hemoglobin electrophoresis were performed. The subjects were followed up on for 1 year in terms of infections. RBC, hemoglobin, reticulocyte count and normoblast count were higher in the newborns of hypertensive mothers compared to the control group, and total leukocytes, neutrophil, lymphocyte, monocyte, eosinophil, and thrombocyte counts were lower. The number of neutropenic and thrombocytopenic subjects in newborns of hypertensive mothers was higher compared to the control group. On peripheral smears, dysplastic changes in neutrophils and erythrocytes were observed with a higher rate in newborns of hypertensive mothers compared to the control group. HbF levels were found to be higher in newborns of hypertensive mothers compared to the control group. During the follow-up period of 1 year, the number of infections in newborns of hypertensive mothers was found to be higher than the control group. Conclusion: Newborns of hypertensive mothers should be carefully evaluated and monitored in terms of hematologic abnormalities. Complete blood counts and peripheral blood smears can be used as significant parameters for early diagnosis of possible complications.
\end{abstract}

\footnotetext{
A. Bolat $\cdot$ O. Ozcan

Department of Pediatrics, Gulhane Military Medical Academy and Medical Faculty, Ankara, Turkey

O. Gursel $(\varangle) \cdot$ E. Kurekci $\cdot$ A. Atay

Department of Pediatric Hematology, Gulhane Military Medical

Academy and Medical Faculty, Etlik, 06018 Ankara, Turkey

e-mail: orhangursel08@mynet.com

O. Gursel

e-mail: ogursel@gata.edu.tr
}

Keywords Pregnancy $\cdot$ Hypertension $\cdot$ Newborn $\cdot$ Blood parameters

\section{Introduction}

Hypertensive diseases of pregnancy are classified as preeclampsia-eclampsia, chronic hypertension, preeclampsiaeclampsia developed in the background of chronic hypertension, and transient hypertension [19]. The uteroplacental unit is one of the organs which is affected by capillary damage in hypertensive pregnant women. Early and long-term hypertension may lead to uteroplacental failure, fetal distress, intrauterine growth retardation (IUGR) and preterm delivery. It was shown that the risk of polycythemia was higher in babies of hypertensive mothers compared to the general population and maternal hypertension constituted a significant risk for polycythemia independent of fetal growth [12]. It has been reported that nucleated red blood cells increase secondary to uteroplacental hypoperfusion in babies of preeclamptic mothers [17]. In addition, it was shown that the possibility of thrombocytopenia was higher in newborns of preeclamptic mothers who had hypertension and especially thrombocytopenia, compared to normotensive mothers [4, 16]. Preeclampsia has been reported to be a risk factor for neonatal neutropenia and infections in premature newborns [6]. Therefore, early detection and prophylactic treatment are recommended in newborns at high risk.

Newborns of hypertensive mothers have a risk for polycythemic, infectious, and bleeding complications. However, there is no study comprehensively investigating the changes in hematologic parameters in the newborns which may be caused by hypertension in the mothers. In this study, the changes in the hematologic parameters were investigated in newborns of hypertensive mothers, including the morphologies of blood cells. 


\section{Materials and methods}

Thirty-one pregnant women with a diagnosis of hypertension for at least 3 months and their newborns constituted the study group, and 32 healthy pregnant women and their newborns constituted the control group. Arterial blood pressure $\geq 140 / 90 \mathrm{mmHg}$ was defined as hypertension. Women who have hypertension with proteinuria and/or edema that happens after 20th gestational week were defined as preeclamptic pregnant women. Women who have hypertension without the other signs of preeclampsia that happens during the pregnancy were defined as pregnant women with transient hypertension. Women who had hypertension also before the pregnancy or whose blood pressure $\geq 140 / 90 \mathrm{mmHg}$ before the 20th gestational week were defined as chronic hypertensive pregnant women [19]. Newborns whose mothers used another drug in addition to anti-hypertensive drugs, whose mothers had another chronic disease, whose gestational age was $<24-$ weeks, who had chromosomal anomalies, congential metabolic diseases, congenital malformations, premature rupture of membranes, perinatal infections and hematologic or endocrine diseases were excluded from the study.

The demographic data of the mothers (age, chronic disease, drug usage, parity, blood group, gestational week, interventional procedures during pregnancy, problems during pregnancy, mode of delivery, administration of anesthesia, delivery induction, presence of meconium, fetal deceleration and presence of a nuchal cord), birth weight of the newborn, gender of the newborn, Apgar scores at the first and fifth minutes and resuscitation status were recorded. Before the investigations were initiated, the content of the study was explained to the families and written informed consent was obtained.

In all subjects, umbilical cord blood was obtained after delivery and complete blood count, peripheral blood smear, reticulocyte count, serum vitamin $B_{12}$, folate, ferritin levels and hemoglobin electrophoresis analyses were performed. Complete blood count was performed by a hemocytometer after routine daily calibration (Beckman Coulter PN 72377817, 2004 Fullerton, California, USA). Serum vitamin B12 (reference range $200-835 \mathrm{pg} / \mathrm{mL}$ ), folate (reference range $5-21 \mathrm{ng} / \mathrm{mL}$ ) and ferritin levels (reference range 13$150 \mathrm{ng} / \mathrm{mL}$ ) were measured using a Modular Analytics E170 device with electrochemiluminescence immunologic test system (Hitachi Automatic Analyzer 1679-01 Tokyo, Japan) and hemoglobin electrophoresis was performed using a Sebia Hydrasys device with a semi-automatic agaroze gel electrophoresis system (Model 3187, 02/49, France).

In peripheral blood smears, neutrophils were examined in terms of hypersegmentation, nuclear abnormalities (a nucleus with hook, lump, flag-like projections or microlobes and pseudo Pelger-Huet anomalies), cytoplasmic abnormalities (hypogranulation or agranulation and granule distribution abnormalities), and membrane abnormalities (protrusion, loss of integrity). A segmentation index was calculated ([number of neutrophils with $\geq 5$ lobes/number of neutrophils with 4 lobes $] \times 100$ ) and a value of $>16.9$ was considered to be abnormal [2]. Smears with $2 \%$ or more damaged nuclei was considered a nuclear structural defect, smears with $2 \%$ or more hypogranulation was considered agranulation, smears with granule distribution abnormalities were considered cytoplasmic granule defects and smears with loss of membrane integrity were considered membrane abnormalities. One hundred thrombocytes were examined to detect the presence of giant thrombocytes $(>20 \%$ of thrombocytes with a diameter of $>4 \mu \mathrm{m}$ and $>3 \%$ of thrombocytes with a diameter $>8 \mu \mathrm{m}$ ). The detected erythrocyte anomalies (spherocytes, poikilocytosis, polychromasia, anisocytosis, etc.) were also recorded.

Statistical analysis The data were analyzed and processed in the computer using SPSS for Windows 11.0 Package program. In descriptive statistics, numbers and percentages were used for discontinuous variables, mean \pm standard deviation and minimum and maximum values were used for continuous variables. Chi-square $\left(\chi^{2}\right)$ was used for comparison of discontinuous variables. The differences between groups were compared using $\mathrm{T}$ tests for the ones with a normal distribution and Mann-Whitney tests for the ones which had no normal distribution. Logistic regression analysis was done to define the risk related to independent variables. A $p$ value of $<0.05$ was considered to be significant.

\section{Results}

Since no mother with eclampsia and acute hypertension developed in the background of chronic hypertension was present in the study group, hypertensive mothers were examined in three groups (preeclampsia, chronic hypertension, and transient hypertension induced by pregnancy).

\section{Demographic findings}

During the study, 31 of 63 neonates with a gestational age between 27 and 39 weeks born in our center were considered the study group and 32 of 63 neonates were considered the control group. The perinatal and neonatal properties of a total of 63 subjects constituting the study group and the control group are shown in Table 1.

There was no difference between the groups in terms of maternal age, parity, gestational week, prematurity state, mode of delivery, interventional procedures during 
Table 1 Prenatal-neonatal properties of the subjects

The values in italics demonstrate that $p$ values less than $<0.05$ and consider to be statistically significant

${ }^{a}$ Values are given as mean \pm SD (standard deviation) (minimummaximum)

${ }^{\mathrm{b}}$ Values are given as numbers (\%)

\begin{tabular}{|c|c|c|c|c|}
\hline \multicolumn{2}{|l|}{ Parameter } & Study group $(n=31)$ & Control group $(n=32)$ & $p$ \\
\hline \multicolumn{2}{|l|}{ Maternal age (years) ${ }^{\mathrm{a}}$} & $28.83 \pm 4.56(21-38)$ & $29.81 \pm 4.77(19-41)$ & 0.41 \\
\hline \multicolumn{5}{|l|}{ Number of the pregnancy ${ }^{\mathrm{b}}$} \\
\hline \multirow{2}{*}{\multicolumn{2}{|c|}{$\begin{array}{l}1 \\
2\end{array}$}} & $19(61.3)$ & $19(59.4)$ & 0.36 \\
\hline & & $9(29.0)$ & $6(18.8)$ & \\
\hline \multicolumn{2}{|l|}{3} & $1(3.2)$ & $3(9.4)$ & \\
\hline \multicolumn{2}{|l|}{4} & $2(6.5)$ & $3(9.4)$ & \\
\hline \multicolumn{2}{|l|}{5} & $0(0)$ & $1(3.1)$ & \\
\hline \multicolumn{2}{|l|}{ Parity $^{\mathrm{a}}$} & $1.54 \pm 0.85(1-4)$ & $1.78 \pm 1.15(1-5)$ & 0.36 \\
\hline \multicolumn{2}{|l|}{ Gestational age (weeks) $^{\mathrm{a}}$} & $34.19 \pm 2.78(27-39)$ & $35.00 \pm 2.75(27-39)$ & 0.25 \\
\hline \multicolumn{2}{|l|}{ Premature $(\leq 37 \text { weeks })^{\mathrm{b}}$} & $25(80.6)$ & $22(68.8)$ & \\
\hline \multicolumn{2}{|c|}{ Mature $(>37 \text { weeks })^{\mathrm{b}}$} & $6(19.4)$ & $10(31.2)$ & 0.27 \\
\hline \multicolumn{2}{|c|}{ Mode of delivery (vaginal/Cesarean) } & $2 / 29$ & $5 / 27$ & 0.25 \\
\hline \multirow[t]{3}{*}{ Anesthesia for delivery ${ }^{\mathrm{b}}$} & General & $23(74.2)$ & $10(31.3)$ & 0.002 \\
\hline & Spinal & $6(19.4)$ & $17(53.1)$ & 0.002 \\
\hline & None & $2(6.5)$ & $5(15.6)$ & 0.25 \\
\hline \multicolumn{2}{|c|}{$\begin{array}{l}\text { Interventional procedures } \\
\text { (A/S, CVS, cordosynthesis) }\end{array}$} & $1 / 31$ & $0 / 32$ & 0.36 \\
\hline \multicolumn{2}{|c|}{ Meconium } & $0 / 31$ & $2 / 32$ & 0.15 \\
\hline \multicolumn{2}{|l|}{ Nuchal cord } & $1 / 31$ & $1 / 32$ & 0.98 \\
\hline \multicolumn{2}{|l|}{ Deceleration } & $2 / 31$ & $7 / 32$ & 0.08 \\
\hline \multicolumn{2}{|l|}{ Neonatal resuscitation } & $6 / 31$ & $3 / 32$ & 0.25 \\
\hline \multicolumn{2}{|c|}{ Apgar score at the first minute ${ }^{a}$} & $7.77 \pm 1.76(2-10)$ & $8.40 \pm 0.94(4-9)$ & 0.08 \\
\hline \multicolumn{2}{|c|}{ Apgar score at the fifth minute ${ }^{a}$} & $9.32 \pm 1.42(3-10)$ & $9.81 \pm 0.47(8-10)$ & 0.07 \\
\hline \multicolumn{2}{|c|}{ Birth weight (grams) ${ }^{\mathrm{a}}$} & $2046.12 \pm 727.35(820-3,500)$ & $\begin{array}{r}2595.31 \pm 845.89 \\
(1,000-4,400)\end{array}$ & 0.008 \\
\hline \multicolumn{2}{|l|}{ Gender (male/female) } & $14 / 17$ & $11 / 21$ & 0.39 \\
\hline \multicolumn{2}{|l|}{ Neonatal death } & $1 / 31$ & $0 / 32$ & 0.3 \\
\hline
\end{tabular}

proteinuria was found in $15 \%$. Three mothers who were hypertensive for more than 6 months were considered to be in the chronic hypertension group. Twenty of 28 mothers with a hypertension period of 3-6 months were preeclamptic mothers and the diagnosis for preeclamptic mothers was made before the 20th gestational week. Eight hypertensive mothers were diagnosed as transient hypertension induced by pregnancy, and hypertension started after the 20th gestational week and returned to normal before the 6th week after delivery in these mothers. Seven of the preeclamptic mothers, one of the mothers with transient hypertension induced by pregnancy, and all of the mothers with chronic hypertension were using antihypertensive drugs. Metoprolol was used by chronic hypertensive pregnant women (three women) and nifedipine and $\alpha$ methyl-dopa were used by the pregnant women belonging to the other groups (eight women). No severe side effects were observed with the aforementioned drugs. When the subjects whose mothers used drugs were compared with the subjects who did not use drugs, no significant difference was found in terms of birth weight $(1,781 \pm 788.3$ vs. $2,172.3 \pm 679.7 \mathrm{~g})$, Apgar score at the first minute (7.7 \pm 2.45 vs. $7.8 \pm 1.4)$ and Apgar score at the fifth minute $(8.8 \pm 2.2$ vs. $9.6 \pm 0.8)(p>0.05)$. 
Complete blood count findings

A hemoglobin value of $<13.5 \mathrm{~g} / \mathrm{dl}$ was considered anemia and a venous hematocrit value of $>65 \%$ was considered polycythemia. A neutrophil count of $<1,500 / \mathrm{mm}^{3}$ was considered neutropenia, a lymphocyte count of $<3,000 / \mathrm{mm}^{3}$ was considered lymphopenia and a thrombocyte count of $<150,000 / \mathrm{mm}^{3}$ was considered thrombocytopenia.

Complete blood count parameters of both groups are shown in Table 2 and the state of cytopenic subjects are shown in Table 3.

\section{(a) Erythrocyte indices}

When the two groups were examined in terms of anemia, the study group included one anemic subject, the control group included three anemic subjects, and no significant difference was found between the two groups in terms of anemia $(p=0.31)$. None of the groups included polycythemic subjects. When the two groups were compared in terms of erythrocyte indices, no significant difference was found between the two groups in terms of $\mathrm{MCV}, \mathrm{MCH}$, and $\mathrm{MCHC}$ $(p>0.05)$. RBC, hemoglobin, RDW, reticulocyte percentage, and the number of normoblasts were significantly higher in the study group compared to the controls $(p<0.05)$.

\section{(b) Leukocyte indices}

Among leukocyte indices, total leukocyte, neutrophil, lymphocyte, monocyte and eosinophil counts were found to be lower in the study group compared to the controls $(p<0.05)$.
No difference was found between the two groups in terms of basophil counts $(p>0.05)$.

When the two groups were evaluated in terms of cytopenia, 18 neutropenic subjects ( 4 severely neutropenic, 6 moderately neutropenic, 8 mildly neutropenic), 11 lymphopenic subjects, and 4 neutropenic+lymphopenic ( 1 severely neutropenic, 3 mildly neutropenic) subjects were found in the study group. In the control group, 2 neutropenic subjects and 6 lymphopenic subjects were found. When the cytopenic subjects were examined, the total number of neutropenic subjects in the study group was found to be higher compared to the control group $(p<0.001)$. Among neutropenic subjects, the numbers of mildly, moderately and severely neutropenic subjects were found to be higher in the study group $(p<0.05)$. No difference was found between the two groups in terms of the number of lymphopenic subjects $(p>0.05)$.

\section{(c) Thrombocyte indices}

MPV and PDW values were found to be significantly higher in the study group $(p<0.05)$. Thrombocyte counts in the subjects in the study group were found to be lower compared to the control group $(p<0.001)$.

When the two groups were evaluated in terms of cytopenia, ten thrombocytopenic subjects were found in the study group. Neutropenia and/or lymphopenia were found in thrombocytopenic subjects. There was no subject with isolated thrombocytopenia. No thrombocytopenic subject was found in the control group. Among ten thrombocytopenic subjects in the study group, one subject had a thrombocyte count of $<20,000 / \mathrm{mm}^{3}(10 \%)$, one subject had a thrombocyte count
Table 2 Complete blood count parameters in the subjects of the study group and the control group

The values in italics demonstrate that $p$ values less than $<0.05$ and consider to be statistically significant

${ }^{\mathrm{a}}$ Values are given as mean $\pm \mathrm{SD}$ (minimum-maximum)

\begin{tabular}{llll}
\hline Parameter & Study group $(n=31)$ & Control group 2 $(n=32)$ & $p$ \\
\hline $\mathrm{RBC}\left(\times 10^{6} / \mathrm{mm}^{3}\right)^{\mathrm{a}}$ & $4.4 \pm 0.3(3.8-5.4)$ & $4.1 \pm 0.4(3.3-4.9)$ & 0.02 \\
$\mathrm{Hb}(\mathrm{g} / \mathrm{dl})^{\mathrm{a}}$ & $16.1 \pm 1.4(14.4-19.3)$ & $15.2 \pm 1.1(12.9-17.7)$ & 0.004 \\
$\mathrm{MCV}(\mathrm{fl})^{\mathrm{a}}$ & $111.1 \pm 5.3(101-125)$ & $107.8 \pm 7.8(88-122)$ & 0.11 \\
$\mathrm{MCH}(\mathrm{pg})^{\mathrm{a}}$ & $37.4 \pm 2(34.9-42.2)$ & $36.3 \pm 2.9(29.5-40.7)$ & 0.24 \\
MCHC $(\mathrm{g} / \mathrm{dl})^{\mathrm{a}}$ & $34 \pm 1.3(30.9-37.6)$ & $33.6 \pm 1.1(31.5-35.6)$ & 0.36 \\
RDW $(\%)^{\mathrm{a}}$ & $12.8 \pm 2.7(9.8-18.6)$ & $11 \pm 2(9.7-17.2)$ & 0.02 \\
Reticulocyte $(\%)^{\mathrm{a}}$ & $5.7 \pm 2.7(3.6-15)$ & $3.3 \pm 1.6(1-8)$ & $<0.001$ \\
Normoblast $(\%)^{\mathrm{a}}$ & $10.2 \pm 17.1(2-78)$ & $3.6 \pm 2.8(0-12)$ & 0.014 \\
Leukocytes $\left(\times 10^{3} / \mathrm{mm}^{3}\right)^{\mathrm{a}}$ & $6.9 \pm 3.6(1.6-14.6)$ & $10.7 \pm 3.5(3.7-17)$ & $<0.001$ \\
Neutrophils $\left(\times 10^{3} / \mathrm{mm}^{3}\right)^{\mathrm{a}}$ & $2.1 \pm 2(0.2-9.6)$ & $4.8 \pm 2.4(1.3-10.4)$ & $<0.001$ \\
Lymphocytes $\left(\times 10^{3} / \mathrm{mm}^{3}\right)^{\mathrm{a}}$ & $3.4 \pm 1.9(0.2-8.8)$ & $4.2 \pm 1.9(0.7-9.6)$ & 0.04 \\
Monocytes $\left(\times 10^{3} / \mathrm{mm}^{3}\right)^{\mathrm{a}}$ & $0.8 \pm 0.6(0.1-2.1)$ & $1.2 \pm 0.6(0.3-2.7)$ & 0.01 \\
Eosinophils $\left(\times 10^{3} / \mathrm{mm}^{3}\right)^{\mathrm{a}}$ & $0.2 \pm 0.2(0.01-0.9)$ & $0.3 \pm 0.2(0.01-0.8)$ & 0.009 \\
Basophils $\left(\times 10^{3} / \mathrm{mm}^{3}\right)^{\mathrm{a}}$ & $0.1 \pm 0.1(0.09-0.5)$ & $0.1 \pm 0.1(0.04-0.4)$ & 0.1 \\
Thrombocytes $\left(\times 10^{3} / \mathrm{mm}^{3}\right)^{\mathrm{a}}$ & $168.2 \pm 81.7(16-359)$ & $256 \pm 602.4(121-415)$ & $<0.001$ \\
MPV $(\mathrm{fl})^{\mathrm{a}}$ & $8.9 \pm 1.4(7.4-13.4)$ & $8.1 \pm 0.9(6.8-10)$ & 0.01 \\
PDW $(\%)^{\mathrm{a}}$ & $17.1 \pm 6.6(8.1-33.8)$ & $12.6 \pm 3(8.5-21)$ & 0.02 \\
\hline
\end{tabular}


Table 3 Cytopenic subjects in the study group and the control group

The values in italics demonstrate that $p$ values less than $<0.05$ and consider to be statistically significant

${ }^{a}$ Neutropenic+lymphopenic subjects were also counted in the neutropenic and lymphopenic groups separately

${ }^{\mathrm{b}}$ Since an isolated thrombocytopenic subject was not found, thrombocytopenic subjects were not added to the total count

\begin{tabular}{|c|c|c|c|c|c|}
\hline \multirow[t]{2}{*}{ Parameters } & \multirow{2}{*}{$\begin{array}{l}\text { Study group } \\
(n=31)\end{array}$} & \multirow{2}{*}{$\begin{array}{l}\text { Control group } \\
(n=32)\end{array}$} & \multicolumn{3}{|c|}{ Single-variable logistic regression analysis } \\
\hline & & & OR & $\% 95 \mathrm{CI}$ & $p$ \\
\hline Neutropenia (\%) & $18(58.1)$ & $2(6.2)$ & 20.7 & $4.196-102.796$ & $<0.001$ \\
\hline Mild neutropenia & $8(25.8)$ & $2(6.2)$ & 5.2 & $1.010-26.949$ & 0.034 \\
\hline Moderate neutropenia & $6(19.3)$ & $0(0)$ & - & - & 0.009 \\
\hline Severe neutropenia & $4(12.9)$ & $0(0)$ & - & - & 0.036 \\
\hline Lymphopenia (\%) & $11(35.5)$ & $6(18.7)$ & 2.3 & $0.752-7.549$ & 0.13 \\
\hline $\begin{array}{l}\text { Neutropenia+lymphopenia } \\
(\%)^{\mathrm{a}}\end{array}$ & $4(12.9)$ & $0(0)$ & - & - & $<0.001$ \\
\hline Thrombocytopenia $(\%)^{\mathrm{b}}$ & $10(32.2)$ & $0(0)$ & - & - & $<0.001$ \\
\hline Total & $25(80.6)$ & $8(25)$ & 12.5 & $3.774-41.400$ & 0.001 \\
\hline
\end{tabular}

of $20,000-50,000 / \mathrm{mm}^{3}(10 \%)$ and eight subjects had a thrombocyte count of $50,000-150,000 / \mathrm{mm}^{3}$ (80 \%). Conclusively, 25 of 31 subjects $(80.6 \%)$ in the study group and 8 of 32 subjects $(25 \%)$ in the control group were cytopenic. The number of cytopenic subjects was found to be higher in the study group compared to the controls $(p<0.001)$.

When the subjects in the study group were evaluated in terms of complete blood count parameters between themselves, no significant difference was found between hypertensive groups (preeclampsia, chronic hypertension, and transient hypertension induced by pregnancy) $(p>0.05)$.

\section{Prematurity and premature subjects}

When prematurity was examined in cytopenic subjects, 15 of 18 neutropenic subjects, 8 of 11 lymphopenic subjects, 3 of 4 neutropenic+lymphopenic subjects and 9 of 10 thrombocytopenic subjects were premature in the study group. Both neutropenic subjects and 5 of 6 lymphopenic subjects were premature in the control group. While 20 of 25 cytopenic subjects $(80 \%)$ were premature in the study group, 7 of 8 cytopenic subjects $(87.5 \%)$ were premature in the control group.

When premature subjects were examined, the total number of neutropenic subjects (15 vs. 2) $(p<0.001)$, the number of moderately neutropenic subjects (4 vs. 0$)(p=0.05)$ and the number of thrombocytopenic subjects ( 9 vs. 0$)(p=0.004)$ was found to be higher in the study group. No significant difference was found between the two groups in terms of the number of mildly neutropenic subjects (6 vs. 2), the number of lymphopenic subjects ( 8 vs. 5) and the number of neutropenic+lymphopenic subjects (3 vs. 0) $(p>0.05)$.

Cytopenia was present in 20 of 25 premature subjects $(80 \%)$ in the study group and in 7 of 22 premature subjects $(31.8 \%)$ in the control group. When the rates of cytopenia of premature subjects were compared, the number of cytopenic subjects was again found to be higher in the study group compared to the controls ( $p=0.002)$. In the study group, birth weight of neutropenic subjects was found to be lower compared to non-neutropenic subjects $(p=0.029)$. No significant difference was found between the lymphopenic and thrombocytopenic subjects of the study group and the neutropenic and lymphopenic subjects in the control group in terms of birth weight $(p>0.05)$.

\section{Peripheral smear findings}

Since fragmented neutrophils were found in the peripheral smear of two subjects in group 2, these subjects were excluded from the evaluation performed in terms of neutrophils. Therefore, peripheral smear findings of the control group were evaluated in 30 subjects in terms of neutrophils and in 32 subjects in terms of erythrocytes and thrombocytes.

\section{(a) Erythrocyte findings}

Erythrocyte abnormalities (spherocytosis, anisocytosis, poikilocytosis, and polychromasia) were found in 16 $(51.6 \%)$ of 31 subjects in the study group and in 7 $(21.9 \%)$ of 32 subjects in the control group. The difference was found to be statistically significant $(p=0.014)$.

\section{(b) Leukocyte findings}

There was no significant difference in terms of neutrophil hypersegmentation $(p>0.05)$. Mean number of lobes and abnormality in the segmentation index were found with a higher rate in the study group compared to the controls $(p<0.05)$. Nuclear structural defects were found in $96.7 \%$ of the study group and in $56.6 \%$ of the control group. This difference was considered to be significant $(p<0.001)$. The appearance of a defective nucleus was caused by nuclei with hook, lump, and flag-like projections (Table 4).

Cytoplasmic granular defect was found in $61.3 \%$ of the study group and in $31.2 \%$ of the control group. This difference was significant $(p=0.017)$. Similarly, membrane abnormality, 
Table 4 Comparison of peripheral smear findings of neutrophils in the study group and the control group

The values in italics demonstrate that $p$ values less than $<0.05$ and consider to be statistically significant

${ }^{\text {a }}$ Values are given as mean $\pm \mathrm{SD}$ (minimum-maximum)

${ }^{\mathrm{b}}$ If the index is $>16.9$, the result is abnormal

\begin{tabular}{|c|c|c|c|}
\hline Parameters & $\begin{array}{l}\text { Study group } \\
(n=31)\end{array}$ & $\begin{array}{l}\text { Control group } \\
(n=30)\end{array}$ & $p$ \\
\hline \multicolumn{4}{|l|}{ Nucleus findings } \\
\hline $\begin{array}{l}\text { The number of subjects with neutrophil } \\
\text { hypersegmentation }(\%)\end{array}$ & $2(6.4)$ & $0(0)$ & 0.1 \\
\hline Mean number of lobes ${ }^{\mathrm{a}}$ & $2.32 \pm 0.2(1.87-2.62)$ & $2.03 \pm 0.2(1.2-2.48)$ & $<0.001$ \\
\hline Segmentation index abnormality $(\%)^{\mathrm{b}}$ & $7(22)$ & $1(3.3)$ & 0.03 \\
\hline Nuclear structure defect $(\%)$ & $30(96.7)$ & $17(56.6)$ & $<0.001$ \\
\hline Defective nucleus (in 100 neutrophils) ${ }^{\mathrm{a}}$ & $7.4 \pm 2.9(3-14)$ & $1.8 \pm 1.6(0-5)$ & $<0.001$ \\
\hline \multicolumn{4}{|l|}{ Cytoplasmic findings } \\
\hline Cytoplasmic granule defect (\%) & $19(61.3)$ & $10(33.3)$ & 0.017 \\
\hline Hypogranulation $^{\mathrm{a}}$ & $0.06 \pm 0.2(0-1)$ & $0.09 \pm 0.4(0-2)$ & 1 \\
\hline Agranulation $^{\mathrm{a}}$ & $0.03 \pm 0.2(0-1)$ & $0(0)$ & 0.3 \\
\hline Granule distribution abnormality $^{\mathrm{a}}$ & $2.7 \pm 4(0-22)$ & $0.9 \pm 1.3(0-5)$ & 0.02 \\
\hline Cytoplasmic membrane abnormality (\%) & $11(35.5)$ & $2(6.6)$ & 0.004 \\
\hline Membrane protrusion $^{\mathrm{a}}$ & $0.8 \pm 0.7(0-2)$ & $0.03 \pm 0.2(0-1)$ & 0.006 \\
\hline Loss of integrity of membrane ${ }^{a}$ & $0.7 \pm 1.4(0-7)$ & $0.3 \pm 1.1(0-6)$ & 0.06 \\
\hline
\end{tabular}

was found with a significantly higher rate in the study group compared to the controls ( $35.5 \%$ vs. $6.3 \%, p=0.004)$. In the evaluation of dysplastic findings performed by counting 100 neutrophils, defective nucleus $(7.4 \pm 2.9$ vs. $1.8 \pm 1.6)$, granular distribution abnormality ( $2.7 \pm 4$ vs. $0.9 \pm 1.3$ ), and cytoplasmic membrane protrusion $(0.8 \pm 0.7$ vs. $0.03 \pm 0.2)$ were found with a higher rate in the study group $(p<0.05)$. There was no significant difference between the two groups in terms of hypogranulation, which is one of the cytoplasmic defects $(0.06 \pm 0.2$ vs. $0.09 \pm 0.4)$, agranulation $(0.03 \pm 0.2$ vs. 0$)$, and loss of integrity of cytoplasmic membrane $(0.7 \pm 1.4$ vs. $0.3 \pm 1.1)(p>0.05)$.

\section{(c) Thrombocyte findings}

Although the thrombocyte count was lower and MPV and PDW values were found to be higher in the study group, peripheral smears revealed giant thrombocytes only in three subjects in the study group, the percent of giant thrombocytes in these three subjects was $1 \%$, and thrombocyte counts were $<100,000 / \mathrm{mm}^{3}$. No difference was found between the two groups in terms of percentages of giant thrombocytes $(0.1 \pm 0.3$ vs. 0$)$ and the number of subjects with giant thrombocyte ( 3 vs. 0$)(p=0.07)$. No difference was found between hypertensive groups in terms of peripheral smear findings when the subjects in the study group were evaluated between themselves $(p>0.05)$.

Vitamin B12, folate, ferritin

When serum vitamin B12, folate and ferritin levels were compared between the two groups, no difference was found $(p>0.05)$ (Table 5).

\section{Hemoglobin electrophoresis}

When the two groups were compared in terms of hemoglobin electrophoresis, $\mathrm{Hb} \mathrm{F}$ levels were found to be significantly higher and $\mathrm{Hb} \mathrm{A}$ levels were found to be significantly lower in the study group compared to the controls $(p<0.001)$. There was no significant difference between the two groups in terms of $\mathrm{HbA}_{2}(p>0.05)$ (Table 5).

\section{Follow-up of the subjects}

When the subjects of both groups were evaluated in terms of infections which occurred during a 1 year period, the number of infections diagnosed by a physician was found to be higher in the study group compared to the control group $(6.7 \pm 4.6$ vs. $0.9 \pm 1.1, p<0.001)$ (Table 6). When the infections were classified, the numbers of upper respiratory infections $(4.7 \pm 3.4$, vs. $0.7 \pm 1, p<0.001)$, urinary infections $(0.9 \pm 1.3$ vs. $0.1 \pm 0.2, p<0.001)$, and acute bronchiolitis $(0.7 \pm 1.9$ vs. $0.1 \pm 0.2, p=0.005)$ were found to be higher in the study group compared to the control group. There was no significant difference between the two groups in terms of the number of gastroenteritis $(0.2 \pm 0.6$ vs. $0.1 \pm 0.4, p=0.2)$.

Occurrence of more than eight upper respiratory infections in 1 year is defined as frequent infections. It was observed that the number of frequent infections was higher in the study group compared to the control group ( 9 vs. 0 , $p<0.001)$. Six of nine subjects with frequent infections were found to be neutropenic at birth (three mildly neutropenic, two moderately neutropenic, and one severely neutropenic) and three were found to be neutropenic+lymphopenic. Peripheral smears revealed nuclear structure defects in all 
Table 5 Vitamin B12, folate and ferritin levels and hemoblobin electrophoresis in the study group and the control group

\begin{tabular}{llll}
\hline Parameter & Study group $(n=31)$ & Control group $(n=32)$ & $p$ \\
\hline Vitamin $\mathrm{B}_{12}(\mathrm{pg} / \mathrm{ml})$ & $420.5 \pm 255.1(166.1-1058)$ & $307.6 \pm 131.5(122-653)$ & 0.11 \\
Folate $(\mathrm{ng} / \mathrm{ml})$ & $17.7 \pm 3.3(9.2-20)$ & $17.7 \pm 3.2(10.1-20)$ & 0.89 \\
Ferritin $(\mathrm{ng} / \mathrm{ml})$ & $164.7 \pm 143.8(23.7-848)$ & $198.7 \pm 107.4(102-635)$ & 0.09 \\
$\mathrm{Hb} \mathrm{A}$ & $28.2 \pm 7.9(17-50.9)$ & $36.8 \pm 6.9(20-50.2)$ & $<0.14$ \\
$\mathrm{Hb} \mathrm{A}$ & $0.14 \pm 0.54(0-2.2)$ & $0.10 \pm 0.44(0-2.1)$ & $<01$ \\
$\mathrm{Hb} \mathrm{F}$ & $71.5 \pm 8.4(48.5-82)$ & $63.1 \pm 6.8(49.8-80)$ & $<0.001$ \\
\hline
\end{tabular}

The values in italics demonstrate that $p$ values less than $<0.05$ and consider to be statistically significant

Values are given as mean $\pm \mathrm{SD}$ (minimum-maximum)

subjects, cytoplasmic granule defects in 6 subjects and membrane abnormalities in four subjects.

Follow-up blood values were examined in 10 of 22 cytopenic subjects in the study group. All of these ten subjects were neutropenic at the time of birth (seven neutropenic + thrombocytopenic, three neutropenic + thrombocytopenic + lymphopenic). Blood samples were taken at the age of 1 month from two of these subjects, at the age of 2 months from two subjects, at the age of 10 months from one subject and at the age of 1 year from five subjects. Cytopenia was not found in any of the follow-up blood samples obtained from these subjects.

\section{Discussion}

The frequency of preeclampsia in pregnant women ranges between 10 and $14 \%$ in primigravid women and between 5.7 and $7.3 \%$ in multigravid women [19]. It is mainly observed during the first pregnancy of young mothers. In our study, hypertensive mothers were found to be in the young population and in their first pregnancies. Although there was no significant difference between the two groups in terms of mode of delivery, general anesthesia was performed with a significantly higher rate in the study group compared to the control group, when the procedure of anesthesia during delivery was evaluated. This difference was thought to arise from the fact that general anesthesia was performed at a higher rate among subjects in the study group, who were expected to have complications at a higher rate.

Early and long-term preeclampsia is reported to lead to a decrease in nutrients nourishing the baby and to IUGR [1]. The most commonly observed problem in the baby was growth retardation. In pregnant women with chronic hypertension, the rates of intrauterine growth retardation and fetal mortality are rather high [18]. In our study, birth weights in the study group were found to be significantly lower in the study group compared to the control group. This finding suggested that hypertension in pregnant women caused uteroplacental failure and this led to low birth weight.

In the study performed by Kurlat et al., the risk of polycythemia was shown to be 12.6-fold higher in babies of hypertensive mothers compared to the general population, and it was proven that maternal hypertension constituted a significant risk for polycythemia independent of fetal growth [12]. It has been reported that normoblasts increase in babies of preeclamptic mothers and this is secondary to uteroplacental hypoperfusion [17]. In different studies, hemoglobin, MCV, MCHC, RDW values, and reticulocyte counts were shown to be higher in newborns of preeclamptic mothers [3, 7]. In our study, the finding that erythrocyte counts, hemoglobin value, reticulocyte percent and normoblast count were significantly higher in babies of hypertensive mothers at the time of delivery can be explained by uteroplacental failure and increase in

Table 6 Comparison of the numbers of infections which occurred in the subjects in the study group and the control group during a 1-year follow-up

\begin{tabular}{llll}
\hline Parameters & Group 1 $(n=31)$ & Group 2 $(n=32)$ & $p$ \\
\hline Total number of infections & $6.7 \pm 4.6(2-19)$ & $0.9 \pm 1.1(0-3)$ & $<0.001$ \\
Upper respiratory tract infection & $4.7 \pm 3.4(0-14)$ & $0.7 \pm 1(0-3)$ & $<0.001$ \\
Urinary infection & $0.9 \pm 1.3(0-5)$ & $0.1 \pm 0.2(0-1)$ & $<0.001$ \\
Acute bronchiolitis & $0.7 \pm 1.9(0-10)$ & $0.1 \pm 0.2(0-1)$ & 0.005 \\
Acute gastroenteritis & $0.2 \pm 0.6(0-2)$ & $0.1 \pm 0.4(0-2)$ & 0.2 \\
\hline
\end{tabular}

The values in italics demonstrate that $p$ values less than $<0.05$ and consider to be statistically significant

Values are given as mean $\pm \mathrm{SD}$ (minimum-maximum) 
erythropoesis due to hypoxia. However, no significant difference was found between the two groups in terms of $\mathrm{MCV}$, $\mathrm{MCH}$, and $\mathrm{MCHC}$ values.

Preeclampsia is known to be a risk factor for neonatal neutropenia and thus for infections in premature newborns. Koenig and Christensen suggested that neutropenia was caused by a decrease in growth factors which increase neutrophil production, and decrease in response of progenitor cells to growth factors and presence of inhibitor substance inhibiting neutrophil production [10]. These investigators showed that the activity of colony stimulating factor decreased in the placenta of hypertensive mothers and found an inhibitor substance inhibiting neutrophil production in the placenta. However, decrease in the response of progenitor cells to growth factors could not be shown. In another study, Fas-Fas ligand interaction was reported to be involved in leucopenia in preeclampsia [11]. In another study, it was reported that the balance of erythropoesis and granulopoesis shifted to the direction of erythropoiesis, and because of hypoxia and the resulting increase in reticulopoesis in normal hematopoesis regulation, no adequate stem cells remained for granulopoesis and as a result inadequate granulopoesis was observed and dysgranulopoesis developed [13]. In our study, total counts of leukocytes, neutrophils, lymphocytes, monocytes, and eosinophils were found to be significantly lower in the hypertensive group. These findings are thought to be caused by one or more of the aforementioned mechanisms.

In newborns of preeclamptic mothers, the incidence of thrombocytopenia was shown to be higher compared to the newborns of normotensive mothers $[4,16]$. Although the patophysiologic mechanism underlying thrombocytopenia is not clear, there are studies reporting that it arises from pathology at the placental level [14]. In these studies, it was reported that thrombocytopenia could occur as a result of thrombocyte adherence to the damaged endothelial region caused by segmental vasospasma and vasodilatation in the placenta of hypertensive mothers. Kleckner et al. reported that abnormal placental endothelial surface caused thrombocyte destruction and the resulting thrombocytopenia improved in a short time after delivery [9]. It was also reported that an undefined factor which leads to DIC was transported to the baby by the placenta and caused thrombocytopenia in the newborn [14]. In our study, thrombocyte counts and the number of thrombocytopenic subjects were found to be statistically lower in the hypertensive group. This finding indicates that hypertensive pregnancy is a risk factor for thrombocytopenia in the newborn. The finding that the number of cytopenic subjects was higher in the study group in our study indicates that the newborns of hypertensive mothers carry a higher risk in terms of cytopenia compared to other newborns. The fact that there was no difference between hypertensive groups in the study group in terms of complete blood count parameters suggests that different hypertensive diseases in pregnancy have similar effects in terms of causing cytopenia.

Increase in erythropoiesis, which develops because of uteroplacental failure, and hypoxia can lead to abnormal findings on peripheral smears, including spherocytosis, anisocytosis, and polychromasia $[5,8]$. In our study, the aforementioned erythrocyte abnormalities were found on peripheral smear examinations in $51.6 \%$ of the study group and $21.9 \%$ of the control group. These findings support the fact that displastic changes in newborns of hypertensive mothers are observed at a higher rate.

Although platelet count was found to be low and MPV and PDW values were found to be high in the study group, no significant difference in peripheral smear examinations between the two groups in terms of percentage of giant thrombocytes suggests that the present thrombocytopenia is caused by the moderate response of bone marrow. The fact that no difference was found between the hypertensive subgroups in the study group in terms of peripheral smear findings suggests that different hypertensive diseases of pregnancy have similar effects in terms of causing development of cellular dysplasia.

$\mathrm{HbF}$ has a higher affinity for oxygen compared to $\mathrm{HbA}$. The reason for this is the fact that $\mathrm{HbF}$ does not interact with 2,3-diphosphoglycerate at a significant level, and cells which contain $\mathrm{HbF}$ display a higher oxygen affinity and have the advantage of extracting more oxygen from maternal blood by the placenta. There are studies which showed HbF levels were increased in the umbilical cord in preeclampsia, which is one of the diseases leading to uteroplacental failure, and hypoxia, in addition to studies which showed that $\mathrm{HbF}$ levels were increased also in maternal blood [15, 20]. In our study, $\mathrm{HbF}$ levels were found to be significantly higher in the hypertensive group compared to the control group and $\mathrm{HbA}$ levels were found to be low. This finding was thought to be caused by the stress developed in the fetus by uteroplacental failure and hypoxia.

When the subjects in both groups were evaluated in terms of infections during a 1-year period, it was observed that the number of infections diagnosed by a physician was significantly higher in the study group compared to the control group. Most babies $(72.2 \%)$ who had more frequent infections were found to be neutropenic at birth. In these babies lymphopenia was found at a lower rate $(22.2 \%)$. Nuclear structure defects were found in all of them, cytoplasmic granule defects were found in $66.6 \%$ and membrane abnormalities were found in $38.8 \%$. This suggests that a positive relation is present between frequent infections and neutropenia, and nuclear and cytoplasmic dysplastic changes in neutrophils at birth.

In conclusion, birth weights were found to be lower in newborns of hypertensive mothers because of uteroplacental 
failure and hypoxia compared to the control group and $\mathrm{HbF}$ levels, and erythrocyte counts and $\mathrm{Hb}$ levels were found to be higher. However, it was observed that neutropenia, thrombocytopenia, and dysplastic changes in neutrophils, and erythrocytes on peripheral smears were found at a higher rate in newborns of hypertensive mothers. Newborns of hypertensive mothers carry a risk for complications including primarily infection and bleeding. Therefore, hematologic follow-up should be performed in these newborns. Complete blood counts and peripheral smear examinations are significant laboratory tests which can be used for early diagnosis of hematologic complications in the newborn which may be caused by hypertensive pregnancies.

Acknowledgments This study has been supported by Gulhane Military Medical Academy, Scientific Research Committee.

Conflict of interest The authors declare that they have no conflict of interest.

Open Access This article is distributed under the terms of the Creative Commons Attribution License which permits any use, distribution, and reproduction in any medium, provided the original author(s) and the source are credited.

\section{References}

1. Backes CH, Markham K, Moorehead P, Cordero L, Nankervis CA, Giannone PJ (2011) Maternal preeclampsia and neonatal outcomes. J Pregnancy. doi:10.1155/2011/214365

2. Bain BJ Blood cells: A practical guide. 1st Edn. Gower Medical. London. 34-48

3. Catarino C, Rebelo I, Belo L, Rocha-Pereira P, Rocha S, Bayer Castro E, Patrício B, Quintanilha A, Santos-Silva A (2009) Erythrocyte changes in preeclampsia: relationship between maternal and cord blood erythrocyte damage. J Perinat Med 37:19-27

4. Christensen RD, Henry E, Wiedmeier SE, Stoddard RA, SolaVisner MC, Lambert DK, Kiehn TI, Ainsworth S (2006) Thrombocytopenia among extremely low birth weight neonates: data from a multihospital healthcare system. J Perinatol 26:348353
5. Gordon EA (2003) Polycythemia and hyperviscosity of the newborn. J Perinat Neonatal Nursing 17:209-219

6. Greco P, Manzionna M, Vimercati A, Loverro G, Mautone A, Selvaggi L (1997) Neutropenia in neonates delivered of women with pre-eclampsia. Acta Biomed Ateneo Parmense 68:91-94

7. Heilmann L, Rath W, Pollow K (2005) Fetal hemorheology in normal pregnancy and severe preeclampsia. Clin Hemorheol Microcirc 32:183-190

8. Huang SC, Chang FM (1994) The adverse effect on fetal hemogram by preeclampsia: marked anisocytosis with normocytic, normochromic erythrocythemia as well as thrombocytopenia. Early Hum Dev 37:91-98

9. Kleckner HB, Giles HR, Corrigan JJ (1977) The association of maternal and neonatal trombocytopenia in high risk pregnancies. Am J Obstet Gynecol 128:235-238

10. Koenig JM, Christensen RD (1991) The mechanism responsible for diminished neutrophil production in neonates delivered of women with pregnancy induced hypertension. Am J Obstet Gynecol $165: 467-473$

11. Kuntz TB, Christensen RD, Stegner R, Duff P, Koenig JM (2001) Fas and Fas ligand expression in maternal blood and umbilical cord blood in preeclampsia. Pediatr Res 50:743-749

12. Kurlat I, Sola A (1992) Neonatal polycythemia in appropriately grown infants of hypertensive mothers. Acta Paediatr 81:662-664

13. Moallem M, Koenig JM (2009) Preeclampsia and neonatal neutropenia. NeoReviews 10:454-459

14. Moodley J, Naidu S, Chetty D, Adhikari M, Gouws E (1996) Neonatal trombocytopenia in preeclamptic women with low platelet counts. Hypertens Pregnancy 15:297-304

15. Neumayer E (1966) The fetal $\mathrm{Hb}$ content in umbilical venous blood in newborn infants of mothers with late pregnancy toxemia. Zentralbl Gynecol 88:1348-1350

16. Pritchard JA, Cunningham FG, Pritchard SA, Mason RA (1987) How often does maternal preeclampsia-eclampsia incite thrombocytopenia in the fetus? Obstet Gynecol 69:292-295

17. Salafia CM, Ghidini A, Pezzullo JC, Rosenkrantz TS (1997) Early neonatal nucleated erythrocyte counts in preterm deliveries: clinical and pathologic correlations. J Soc Gynecol Investig 4:138-143

18. Scoot JR (1997) In: Scoot JR, Disaia PJ, Hammond CB, Spellacy WN (eds) Hypertensive disorders of pregnancy. Danforth's Obstetrics and Gynecology Lippincott-Raven, Philadelphia, pp 351-365

19. Sibai BM (1996) Hypertension in pregnancy. In: Gabbe SG, Niebly JR, Simpson JL (eds). Obstetrics Normal \& Problem Pregnancies. Churchill Livingstone pp. 935-987

20. Sinha HB, Mukherjee AK, Bala D (1972) Cord blood haemoglobin (including fetal hemoglobin), and nucleated red cells in normal and toxemic pregnancies. Indian Pediatr 9:540-543 